\title{
The potential risks of paclobutrazol residue on yogurt fermentation from the level of chiral enantiomers
}

\author{
Hao-Ming Guo, Yue Zhao, Mei-Nan Ou Yang, and Zhong-Hua Yang* (1) \\ College of Plant Science and Technology, Department of Plant Protection, Huazhong Agriculture University, Wuhan, 430070, China
}

\section{ABSTRACT}

In recent years, pesticide residues in food have increasingly become the focus of public attention. However, the standard system of pesticide maximum residue limits in fermented food is imperfect, which can lead to potential safety risks to consumers. In this context, the aim of the study was to assess the potential effects of paclobutrazol residue on the yogurt fermentation process. We examined the stereoselective behaviors of the 2 paclobutrazol enantiomers from the perspective of chirality during the yogurt fermentation process. The results indicated that no significant degradation occurred for either of the 2 enantiomers $(2 \mathrm{R}$, 3R-paclobutrazol, 2S, 3S-paclobutrazol), and no visible enantiomer conversion behavior was observed. In addition, the reason paclobutrazol did not significantly degrade was explained from the perspective of the microbial function. Results from $16 \mathrm{~S}$ rRNA sequencing indicated that paclobutrazol significantly affected the microbial composition and inhibited metabolic function of microorganisms to exogenous substances, which impeded the degradation of residual pesticide in yogurt. Furthermore, the stable residue of exogenous substance may cause potential food safety problems. Microbial $\alpha$-diversity analysis indicated that fermentation time played a more important role on diversity than did paclobutrazol concentration. Moreover, Staphylococcus was found in yogurt after treatment with paclobutrazol; Staphylococcus aureus causes dangerous infectious diseases in humans. We devised a method to investigate the presence of pesticide residues during food fermentation and provided a theoretical basis for food safety assessment.

Key words: paclobutrazol, yogurt, food fermentation process, 16S rRNA sequencing

Received November 30, 2019.

Accepted April 9, 2020.

*Corresponding author: yangzhonghua@mail.hzau.edu.cn

\section{INTRODUCTION}

Fermented foods have a long history and are popular among consumers. One traditional fermented dairy product, yogurt, is mostly made by milk and starter with the action of microorganisms (Srisuvor et al., 2013). Yogurt has been proven to have excellent nutritional value on account of its protein, calcium, vitamins, and beneficial microorganisms (Belli et al., 2013; Danneskiold-Samsøe et al., 2019). Therefore, long-term consumption of yogurt is good for human health.

Pesticides play an important role in agricultural production due to their high effectiveness for controlling pests and protecting crops. However, with the extensive use of pesticides, more pesticides are retained and enriched in the environment (Pimentel, 1995; Muñoz-Leoz et al., 2011; Zhi and Ji, 2012; Tejada et al., 2017), and pesticide residues affect food safety (Gao et al., 2019). Many reports illustrate that pesticides are directly toxic to microorganisms and other organisms (Russell et al., 2011; Chen et al., 2019). Recently, Zhang et. al (2019) proved that exogenous substances may change the composition of a microbial community, thus affecting the fermentation process. Yogurt produces plentiful microorganisms during fermentation, which play an important role in the formation of nutritional value and flavor in fermented foods (McMurtrie et al., 2019). It is worrisome that pesticide residues in raw materials may have an effect on the composition of the microbial community, potentially compromising the quality and safety of yogurt (Leite et al., 2012). Nonetheless, few studies have investigated the effects of pesticides on microorganisms produced during yogurt fermentation and the standard system of pesticide maximum residue limit in fermented foods. Therefore, the safety of fermented food is a problem worthy of attention, and the composition, function, and diversity of microorganisms during yogurt fermentation deserves further study.

Paclobutrazol [(2RS, 3RS)-1-(4-chlorophenyl)-4,4dimethyl-2-(1H-1,2,4- trizol-1-yl) pentan-3-ol] is one of the most commonly used plant growth regulators in the world (Gilley and Fletcher, 1998). Paclobutrazol consists of 2 isomers that have different bioactivities. The form 
of (2S,3S)-paclobutrazol (S-paclobutrazol) is active as a plant growth regulator, and (2R,3R)-paclobutrazol (R-paclobutrazol) has high fungicidal activity (Sugavanam, 1984). Although the products and applications of paclobutrazol are in racemic forms, and chiral pesticides may exhibit stereoselective behaviors when they enter into the environment (Yang and Ji, 2015; Zhi et al., 2015), only a few reports have examined the differences between the 2 enantiomers. Paclobutrazol has fungitoxicity by inhibiting the synthesis of ergosterol in fungi (Yun et al., 2014), and has been demonstrated to negatively affect microbial communities and nontarget organisms (Chen et al., 2019; Kuo et al., 2019; Liu et al., 2019). Furthermore, the main target organisms of paclobutrazol are plants. Some researchers have demonstrated that contamination of feed, with aflatoxins or pesticides, for example, can cause cows to produce contaminated milk (Xiong et al., 2018). Therefore, residual paclobutrazol in treated plants may enter a cow's body as she feeds, eventually contaminating the milk and resulting in food safety risks.

Recently, high-throughput sequencing technology has proven to be a valuable tool for the analysis of sample microbial information. By using this technology, some researchers studied stress responses, potential functions, and metabolic capacities of microbial isolates from fermented foods such as kefir and cheese (Zhi et al., 2014; Liu et al., 2015). In addition, some studies focused on investigating the microbial community composition of fermented foods (Wolfe et al., 2014; Bourrie et al., 2016). The 16S rRNA sequencing is one type of highthroughput sequencing technology, and has been widely used to study the composition, diversity, and dynamics of microbial communities that can influence the quality and character of fermented dairy foods (Marsh et al., 2013; Kergourlay et al., 2015).

In this study, we applied high-throughput sequencing technology to pesticide residue analysis to study the stereoselective behaviors and influence of paclobutrazol in 2 yogurt fermentation systems. Information from this study may aid in predicting potential risks to fermented food and human health after the application of chiral pesticides, as well as provide a method for the safety assessment of pesticide residues in food.

\section{MATERIALS AND METHODS}

\section{Chemicals and Reagents}

Paclobutrazol (standards) were obtained from the Institute for Control of Agrichemicals at the China Ministry of Agriculture (Beijing, China). Standards of the 2 optically pure isomers were prepared from Green Herbs
Co. Ltd. (Beijing, China). The stock standard solution $(1 \mathrm{mg} / \mathrm{mL})$ was dissolved by acetone and stored at $4^{\circ} \mathrm{C}$ in darkness. Analytical-grade methanol, acetonitrile, anhydrous sodium sulfate, and sodium chloride were purchased from Sinopharm Chemical Reagent Co. Ltd. (Shanghai, China). The purification materials primary secondary amine (PSA) and $\mathrm{C}_{18} \mathrm{E}$ were purchased from Welch Materials Inc. (Shanghai, China). The ultrapure water was made by a Milli-Q system (Bedford, MA). The HPLC-grade methanol was obtained from Fisher Scientific (Fair Lawn, NJ). Milk was purchased from China Mengniu Dairy Company (Hohhot, Inner Mongolia, China) and commercial yogurt was purchased from Inner Mongolia Yili Industrial Group Limited (Hohhot, Inner Mongolia, China) by Share Ltd. Baking powder was purchased from Angel Yeast Co. Ltd. (Yichang, Hubei, China).

\section{Fermentation Pretreatment}

To compare the differences in composition, diversity, and function of fermented microbes under different conditions, 2 fermentation systems with 2 different starters (commercial yogurt and commercial baking powder) were conducted. The fermentation process followed a previous method by Benozzi et al., (2015). We weighed $250.0 \mathrm{~g}$ of milk and $12.5 \mathrm{~g}$ of commercial yogurt into the fermentation container, and the entire fermentation process lasted $24 \mathrm{~h}$. All the above operations were conducted in the dark at $42^{\circ} \mathrm{C}$. When baking powder was the starter, we used $0.25 \mathrm{~g}$ of commercial baking powder (instead of $12.5 \mathrm{~g}$ of commercial yogurt); all other conditions were the same. The microbes of commercial yogurt were Lactobacillus bulgaricus, Bifidobacterium animalis ssp. lactis, and Streptococcus thermophilus; the microbes of commercial baking powder were $L$. bulgaricus, $B$. animalis ssp. lactis, S. thermophilus, Bifidobacterium longum, Bifidobacterium breve, Bifidobacterium adolescentis, Bifidobacterium bifidum, Bifidobacterium infantis, Lactobacillus acidophilus, and Lactobacillus reuteri.

\section{Sample Contamination and Sampling}

To evaluate the potential influence of xenobiotic substances on fermented microbes, 0.5 or $1.0 \mathrm{~mL}$ of paclobutrazol stock standard solution $(1 \mathrm{mg} / \mathrm{mL})$ was added into each yogurt container, yielding final analyte concentrations of 2 and $4 \mathrm{mg} / \mathrm{kg}$ of paclobutrazol, respectively. Our different samples consisted of commercial yogurt, no contamination $(\mathbf{C K})$, commercial yogurt $(2 \mathrm{mg} / \mathrm{kg}$ of paclobutrazol; L), commercial yogurt $(4 \mathrm{mg} / \mathrm{kg}$ of paclobutrazol; $\mathbf{H})$, commercial baking powder, no contamination (TC), commercial 
baking powder $(2 \mathrm{mg} / \mathrm{kg}$ of paclobutrazol; TL $)$ and commercial baking powder $(4 \mathrm{mg} / \mathrm{kg}$ of paclobutrazol; TH), respectively. The samples for quantitative analysis were collected according to the appropriate time points $(0,4,8,12$, and $24 \mathrm{~h})$ and stored at $-20^{\circ} \mathrm{C}$, and samples collected for DNA isolation were stored at $-80^{\circ} \mathrm{C}$. We compared the following treatment/ timepoint combinations: yogurt fermented with starter culture without paclobutrazol at the beginning of fermentation (CKOh), yogurt fermented with yogurt as starter culture without paclobutrazol at the end of fermentation (CK24h), yogurt fermented with yogurt as starter culture with $4 \mathrm{mg} / \mathrm{kg}$ of paclobutrazol at the end of fermentation $(\mathbf{H 2 4 h})$, yogurt fermented with yogurt as starter culture with $2 \mathrm{mg} / \mathrm{kg}$ of paclobutrazol at the end of fermentation ( $\mathbf{L} \mathbf{2 4 h}$ ), yogurt fermented with baking powder without paclobutrazol at the beginning of fermentation (TCOh), yogurt fermented with baking powder without paclobutrazol at the end of fermentation (TC24h), yogurt fermented with baking powder with $2 \mathrm{mg} / \mathrm{kg}$ of paclobutrazol at the end of fermentation (TL24h), and yogurt fermented with baking powder with $4 \mathrm{mg} / \mathrm{kg}$ of paclobutrazol at the end of fermentation (TH24h).

\section{Sample Pretreatment}

The extraction method was based on a modified QuEChERS method (Di et al., 2019). We weighed 10.0 $\mathrm{g}$ of sample and added it into a 50-mL polypropylene centrifuge tube. Then, $20 \mathrm{~mL}$ of acetonitrile and $2.0 \mathrm{~g}$ of sodium chloride were added into the tube and immediately covered. The mixture was stirred for $5 \mathrm{~min}$ on a vortex mixer, followed by ultrasonic extraction (Kunshan Ultrasonic Instrument Co. Ltd., Jiangsu, China) for $10 \mathrm{~min}$. After extraction, the sample was centrifuged at 3,500 $\mathrm{rpm}$ for $5 \mathrm{~min}$. We repeated the above steps 3 times to ensure high extraction efficiencies. The combined supernatant was passed through a funnel with $5 \mathrm{~g}$ of anhydrous sodium sulfate into the pear-shaped flask. After, the extraction solvent was dried by vacuum rotary evaporation at $40^{\circ} \mathrm{C}$. Next, 1 $\mathrm{mL}$ of methanol was used to dissolve the dried extraction solvent again and move it to a 2-mL centrifuge tube containing $100 \mathrm{mg}$ of $\mathrm{C}_{18} \mathrm{E}$ and $100 \mathrm{mg}$ of PSA. The mixture was stirred for 3 min on a vortex mixer for purification and centrifuged at 8,000 rpm for $5 \mathrm{~min}$. The supernatant was passed through a $0.22-\mu \mathrm{m}$ filter membrane into a $2-\mathrm{mL}$ sample vial. Finally, a $20-\mu \mathrm{L}$ aliquot of the extract sample was injected into the HPLC.

\section{HPLC Analysis}

Paclobutrazol enantiomers were separated and determined on an Agilent 1260 HPLC (Santa Clara, CA) equipped with a G1311A pump, G1322A degasser, G1329A ALS, and G1314B VWD. The injection volume was $20 \mu \mathrm{L}$, and UV detection wavelength was $230 \mathrm{~nm}$. The signal was received and processed by using Agilent ChemStation software. The mobile phase was mixture of methanol and water $(70 / 30, \mathrm{vol} / \mathrm{vol})$ with a flow rate of $0.8 \mathrm{~mL} / \mathrm{min}$ at $30^{\circ} \mathrm{C}$. The chiral column was CDMPC-CSP (cellulose-tri [3, 5-dimethylphenylcarbamate], W250 $\times 4.6 \mathrm{~mm}$ id) purchased from Welch Materials, Inc. (Shanghai, China) and the column temperature was controlled by an AT-930 heater and cooler column attemperator (Tianjin Automatic Science Instrument Co. Ltd., Tianjin, China).

For quality control in the determination of the target analytes, a recovery study of R-paclobutrazol and Spaclobutrazol at different levels ( 1 and $5 \mathrm{mg} / \mathrm{kg}$ of paclobutrazol) was conducted to ensure the accuracy and precision of the method. In the blank yogurt sample, different concentrations of paclobutrazol solution were added (1 and $5 \mathrm{mg} / \mathrm{kg}$ of paclobutrazol). Extraction and HPLC analysis were performed using the above methods. The recovery of the 2 enantiomers was analyzed and is displayed in Table 1.

Table 1. Recoveries and relative standard deviations (RSD) of samples spiked with paclobutrazol $(\mathrm{n}=3)$

\begin{tabular}{|c|c|c|c|c|c|c|c|}
\hline Sample & Chemical & $\begin{array}{l}\text { Paclobutrazol } \\
(\mathrm{mg} / \mathrm{kg})\end{array}$ & \multicolumn{3}{|c|}{ Recovery (\%) } & Average (\%) & RSD (\%) \\
\hline \multirow[t]{3}{*}{ Yogurt } & R-paclobutrazol & 1 & 94.20 & 92.92 & 84.83 & 90.65 & 4.58 \\
\hline & R-paclobutrazol & 5 & 85.86 & 92.92 & 86.50 & 88.43 & 3.61 \\
\hline & S-paclobutrazol & & 86.43 & 97.39 & 89.60 & 91.14 & 5.05 \\
\hline Milk & R-paclobutrazol & 1 & 95.20 & 99.16 & 93.99 & 96.12 & 4.32 \\
\hline
\end{tabular}




\section{DNA Extraction and Sequencing Analysis}

The total genetic DNA of the yogurt was extracted and purified by the PowerSoil DNA Isolation kit (MO BIO Laboratories, Carlsbad, CA). For the amplification of the V3-V4 region of the $16 \mathrm{~S}$ rRNA gene, $338 \mathrm{~F}$ (5'-ACTCCTACGGGAGGCAGCA-3') and 806R (5'-GGACTACHVGGGTWTCTAAT-3') were used as forward and reverse primers, respectively. The PCR reaction conditions were as follows: $2 \mathrm{~min}$ at $98^{\circ} \mathrm{C}$ followed by 30 cycles at $98^{\circ} \mathrm{C}$ for $30 \mathrm{~s}, 50^{\circ} \mathrm{C}$ for $30 \mathrm{~s}$, and $72^{\circ} \mathrm{C}$ for $1 \mathrm{~min}$, and finally at $72^{\circ} \mathrm{C}$ for $5 \mathrm{~min}$. The main microbial communities of the tested samples were detected based on Illumina MiSeq 2500 platform (Illumina Inc., San Diego, CA). The sequenced bacteria genomes deposited in GenBank were downloaded from National Center for Biotechnology Information (NCBI) database (http://www.ncbi.nlm.nih.gov/) for downstream analyses. If the similarity between sequences was higher than $97 \%$, it was defined as an operational taxonomic unit (OTU), and each OTU corresponds to a representative sequence. An E-value $<0.01$ means the results were credible.

\section{RESULTS AND DISCUSSION}

\section{Method Validation}

To evaluate the accuracy of sample pretreatment method, we investigated linearity, correlation coefficient, the recovery of paclobutrazol in the samples, relative standard deviations, and limit of detection (LOD). A dilution series of paclobutrazol spiked samples was prepared and analyzed to checking the method with linear calibration. Good linearity was achieved in all cases with correlation coefficients better than 0.9982 . The complexity of the sample matrix may have affected the experiment results; therefore, all samples were spiked with paclobutrazol at 1 and $5 \mathrm{mg} / \mathrm{kg}$ and the results are summarized in Table 1 . The recoveries of the 2 paclobutrazol enantiomers ranged from 88.43 to $99.61 \%$, with relative standard deviations ranging from 2.98 to $5.05 \%$. The LOD for target analytes were calculated at a signal to noise ratio of 3 , and the LOD values of Spaclobutrazol and R-paclobutrazol were 0.42 and 0.39 $\mathrm{mg} / \mathrm{L}$, respectively. These results indicated that the sample pretreatment method developed in this work performed well in quantitating the target analytes.

The relative HPLC chromatogram is shown in Figure 1 and demonstrates that the 2 paclobutrazol enantiomers could completely separate with a resolution of 5.76 under the established chromatographic conditions. According to the studies, the first peak was (2R,3R)- paclobutrazol and the second peak was (2S,3S)-paclobutrazol (Wang et al., 2014; Wu et al., 2015).

\section{Stereoselective Behaviors of Paclobutrazol During Yogurt Fermentation}

To investigate the stereoselective behaviors of paclobutrazol under different conditions, 2 fermentation systems (commercial yogurt as starter and commercial baking powder as starter) with 2 paclobutrazol concentration levels were conducted. During $24 \mathrm{~h}$ of fermentation, samples were collected and detected at 5 time points $(0,4,8,12$, and $24 \mathrm{~h})$. The change trend of paclobutrazol enantiomers in the fermentation systems when yogurt was treated with $4 \mathrm{mg} / \mathrm{kg}$ of paclobutrazol racemate during fermentation is shown in Figure $2 \mathrm{~A}$ and $2 \mathrm{~B}$. The concentrations of the 2 paclobutrazol isomers did not change and no significant degradation was observed. The same results were obtained when the spiked concentration was $2 \mathrm{mg} / \mathrm{kg}$ of paclobutrazol. The reasons for this might be that the yogurt fermentation time was short and no microorganisms that could degrade paclobutrazol were produced during the fermentation process.

In this study, the enantiomer fraction (EF) was used to evaluate the enantioselectivity and it was calculated as follows:

$$
\mathrm{EF}=\frac{[\mathrm{R}]}{[\mathrm{S}]+[\mathrm{R}]},
$$

where $[R]$ refers to the concentration of $\mathrm{R}-(-)-$ enantiomer, and $[\mathrm{S}]$ refers to the concentration of S(+)-enantiomer. Consequently, an EF $>0.5$ indicates faster degradation of the S-(+)-enantiomer, an $\mathrm{EF}<0.5$ indicates faster degradation of the $\mathrm{R}-(-)$-enantiomer, and a value of 0.5 indicates that the degradation process is nonenantioselective. The changing trend of EF values are shown in Figure 2C and 2D when the spiked concentration was $4 \mathrm{mg} / \mathrm{kg}$ paclobutrazol. Results demonstrate that there were no significant stereoselective behaviors in any of the samples. The same results were obtained when the spiked concentration was $2 \mathrm{mg} / \mathrm{kg}$ of paclobutrazol.

\section{Sequencing Data Quality}

High-throughput sequencing was conducted on 8 group samples: CK0h, CK24h, L24h, H24h, TC0h, TC24h, TL24h, TH24h (0 and $24 \mathrm{~h}$ indicate the beginning and end of fermentation). A total of $1,686,669$ paired-end reads were observed. Clean tags were ob- 


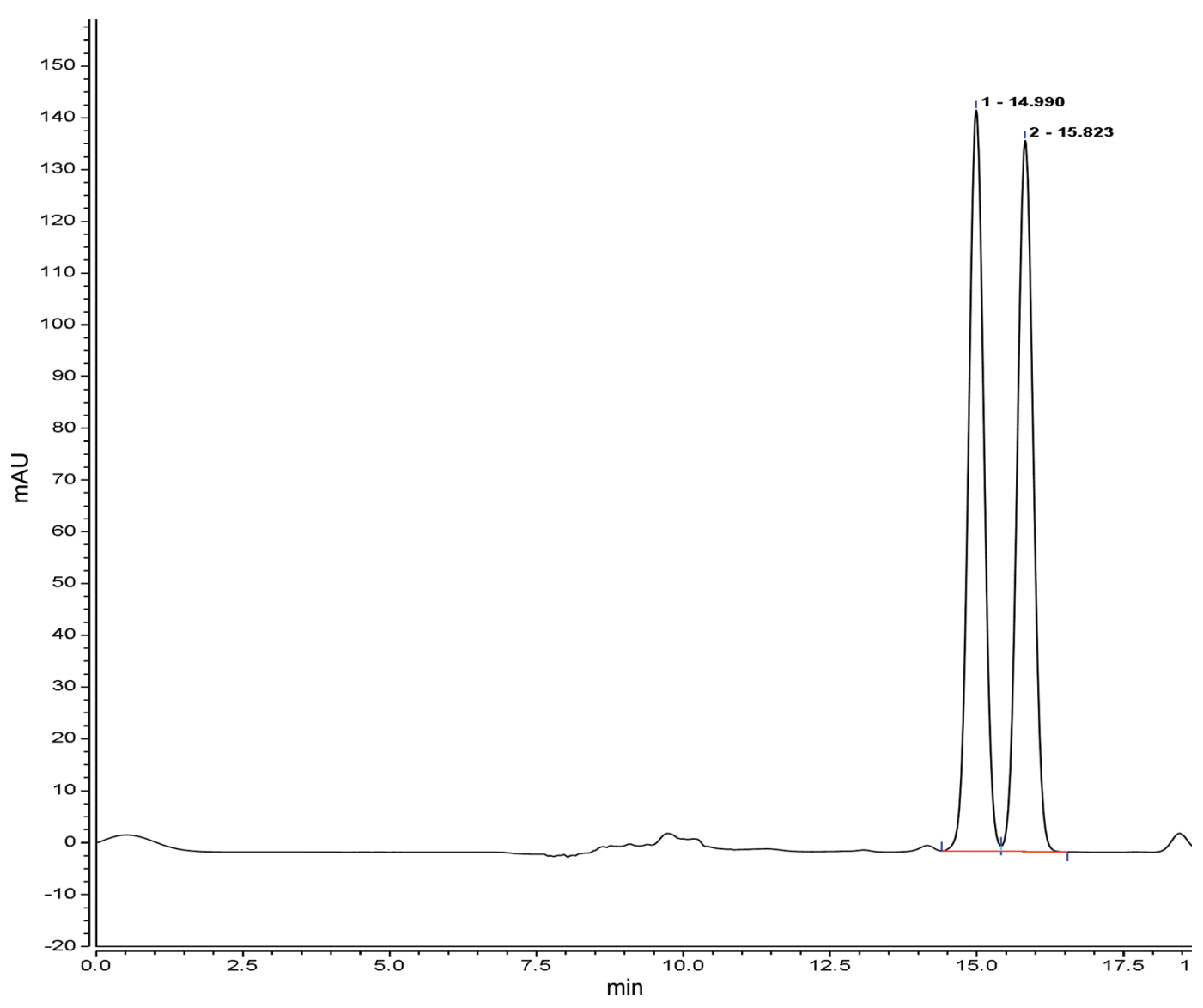

Figure 1. The relative HPLC chromatogram of paclobutrazol.

tained from raw tags after cleaning, and 1,391,040 tags were available, with average length from 427 to $430 \mathrm{bp}$. There were 1,359,268 effective tags, and the average effective percent was $80.53 \%$. The detected OTU in different samples are shown in Table 2, and a total of 97 OTU were detected with clustering at $97 \%$ similarity.

\section{Bacterial Composition of Yogurt Samples}

To evaluate the potential influence of paclobutrazol on fermented microbes, we analyzed $16 \mathrm{~S}$ rRNA sequencing. Results from Figure 3 indicate that the dominant bacteria were Lactobacillus and Streptococcus in all samples. However, the composition and relative abundances of fermented bacteria were different depending on different fermentation systems and sampling times.

Figure 3A shows the relative abundances of fermented bacteria with commercial yogurt as starters. In the initial fermentation process, Streptococcus and Lactobacillus were dominant in CKOh (solvent control), and the relative abundances were 81.59 and $6.09 \%$, respectively. After $24 \mathrm{~h}$ of fermentation, the relative abundances of Streptococcus were decreased to 50.05, 50.46, and $54.52 \%$ in CK24h, L24h, and H24h, respectively. However, the relative abundances of Lactobacillus were 49.82, 49.21, and 45.24\% in CK24h, L24h, and H24h, respectively. There was a significant increase in the relative abundance of Lactobacillus compared with that at the beginning of fermentation $(P<0.01, Q<0.01)$. The $Q$-value was calculated from the $P$-value, and it means that the relative abundance of Lactobacillus in CK0h was significantly different from CK24h, L24h, and H24h. This implies that Lactobacillus became the major flora at the end of fermentation.

From Figure 3B we show that Streptococcus (59.32\%), Lactobacillus (29.68\%), Bifidobacterium (5.98\%), and Weissella $(3.33 \%)$ were the dominant bacteria in TCOh (solvent control), with commercial baking powder as starters. After $24 \mathrm{~h}$ of fermentation, the relative abundances of Streptococcus were decreased and Lactobacillus were increased, which was consistent with the commercial yogurt starters. It was noteworthy that the relative abundances of Staphylococcus significantly increased in TL24h compared with TC24h. Previous studies indicate that Staphylococcus is a widely distributed gram-positive bacterium (Wertheim et al., 2005), 
and can be detected in air, water, and a variety of foods (Pastells et al., 2015). Notably, Staphylococcus as a pathogen can cause many dangerous infectious diseases, such as pneumonia and septicemia (Borsa et al., 2016; Meng et al., 2017), and Staphylococcus can induce skin abscesses in mice (Lei et al., 2018). Other studies demonstrated Staphylococcus can produce enterotoxins in food processing, and consequently, a risk of food poisoning (Schelin et al., 2017; Guidi et al., 2018; Grispoldi et al., 2019). The residue of paclobutrazol could affect the microbial system during yogurt fermentation processing, which will affect the quality of the final yogurt. In addition, the microorganism which could degrade paclobutrazol was not found, and further explained why the concentration of paclobutrazol did not change.

\section{Alpha-Diversity of Bacterial Community}

In this work, the alpha-diversities of different treatment groups were analyzed and compared. The diversity indexes, which contained OTU, ACE, Chao
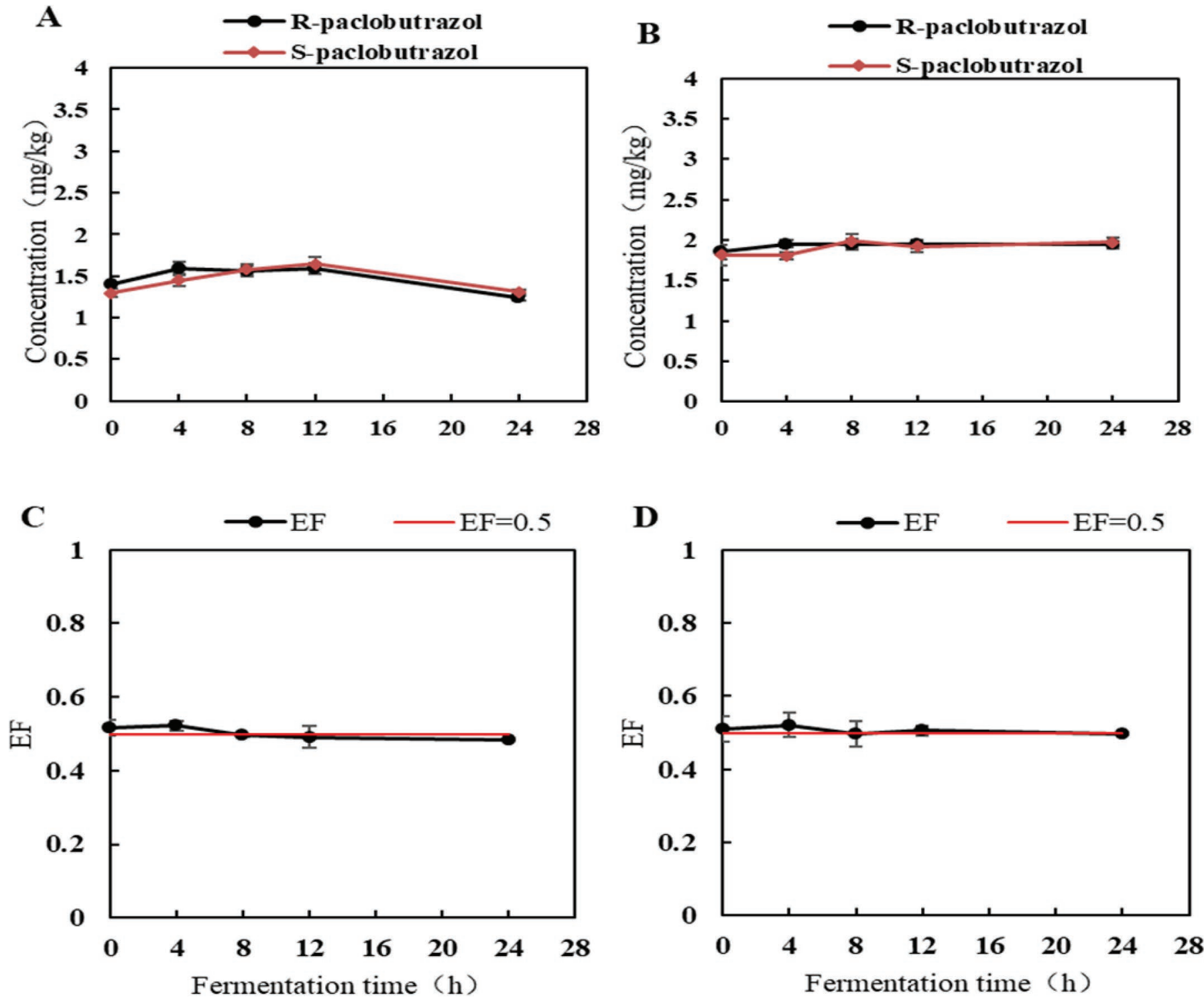

Figure 2. The changes in paclobutrazol concentration in isomers and enantiomer fraction (EF) value during yogurt fermentation process (A $=$ yogurt fermented with yogurt starter, $4 \mathrm{mg} / \mathrm{kg}$ of paclobutrazol; $\mathrm{B}=$ yogurt fermented with baking powder, $4 \mathrm{mg} / \mathrm{kg}$ of paclobutrazol; $\mathrm{C}=$ yogurt fermented with yogurt starter, $4 \mathrm{mg} / \mathrm{kg}$ of paclobutrazol; D = yogurt fermented with baking powder, $4 \mathrm{mg} / \mathrm{kg}$ of paclobutrazol). An EF value of 0.5 indicates that the degradation process was nonenantioselective. An EF near EF $=0.5$ means the degradation of paclobutrazol was nonenantiomerselective. 
Table 2. Operational taxonomic unit (OTU) and $\alpha$-diversity of microbial communities at initial time $(0 \mathrm{~h})$ and after $24 \mathrm{~h}$ of fermentation

\begin{tabular}{lllccc}
\hline & \multicolumn{5}{c}{ Diversity index } \\
\cline { 2 - 5 } Sample $^{1}$ & OTU $_{97}$ & ACE & Chao1 & Simpson & Shannon \\
\hline CK0h & $84.67^{\mathrm{a}}$ & $85.17^{\mathrm{a}}$ & $85.67^{\mathrm{a}}$ & $0.65^{\mathrm{a}}$ & $1.16^{\mathrm{ab}}$ \\
CK24h & $28.33^{\mathrm{c}}$ & $56.64^{\mathrm{a}}$ & $40.84^{\mathrm{b}}$ & $0.50^{\mathrm{bcd}}$ & $0.70^{\mathrm{c}}$ \\
H24h & $37.00^{\mathrm{bc}}$ & $72.94^{\mathrm{a}}$ & $53.79^{\mathrm{b}}$ & $0.50^{\mathrm{bcd}}$ & $0.71^{\mathrm{c}}$ \\
L24h & $30.33^{\mathrm{bc}}$ & $52.27^{\mathrm{a}}$ & $40.82^{\mathrm{b}}$ & $0.50^{\mathrm{cd}}$ & $0.72^{\mathrm{c}}$ \\
TC0h & $44.33^{\mathrm{bc}}$ & $51.72^{\mathrm{a}}$ & $52.73^{\mathrm{b}}$ & $0.40^{\mathrm{d}}$ & $1.35^{\mathrm{a}}$ \\
TC24h & $75.00^{\mathrm{a}}$ & $82.14^{\mathrm{a}}$ & $80.28^{\mathrm{ab}}$ & $0.55^{\mathrm{abc}}$ & $0.90^{\mathrm{bc}}$ \\
TH24h & $39.67^{\mathrm{bc}}$ & $53.16^{\mathrm{a}}$ & $48.78^{\mathrm{b}}$ & $0.65^{\mathrm{a}}$ & $0.67^{\mathrm{c}}$ \\
TL24h & $46.33^{\mathrm{b}}$ & $73.95^{\mathrm{a}}$ & $68.57^{\mathrm{ab}}$ & $0.64^{\mathrm{ab}}$ & $0.67^{\mathrm{c}}$ \\
\hline
\end{tabular}

${ }^{\mathrm{a}-\mathrm{d}}$ Different superscripts indicate significance in different samples.

${ }^{1} \mathrm{CK}=$ yogurt fermented with yogurt starter, no contamination; $\mathrm{H}=$ yogurt fermented with yogurt starter, 4 $\mathrm{mg} / \mathrm{kg}$ of paclobutrazol; $\mathrm{L}=$ yogurt fermented with yogurt starter, $2 \mathrm{mg} / \mathrm{kg}$ of paclobutrazol; TC = yogurt fermented with baking powder, no contamination; $\mathrm{TH}=$ yogurt fermented with baking powder, $4 \mathrm{mg} / \mathrm{kg}$ of paclobutrazol; TL = yogurt fermented with baking powder, $2 \mathrm{mg} / \mathrm{kg}$ of paclobutrazol.

1, Simpson, and Shannon, are shown in Table 2. An increase in the Simpson value indicated a low diversity of bacteria. Conversely, an increase in the Chao1, ACE, and Shannon values indicated an increase in the diversity of bacteria. High microbial diversity could be found in $\mathrm{CKOh}$ and $\mathrm{TCOh}$, and as fermentation progressed, bacterial diversity decreased. This phenomenon could be attributed to the proliferation of dominant bacteria during fermentation. Moreover, the diversity of bacteria in TH24h was lower than that in TC24h; this suggested that different concentrations of paclobutrazol could affect alpha-diversity, and a relatively high concentration of paclobutrazol reduced diversity.

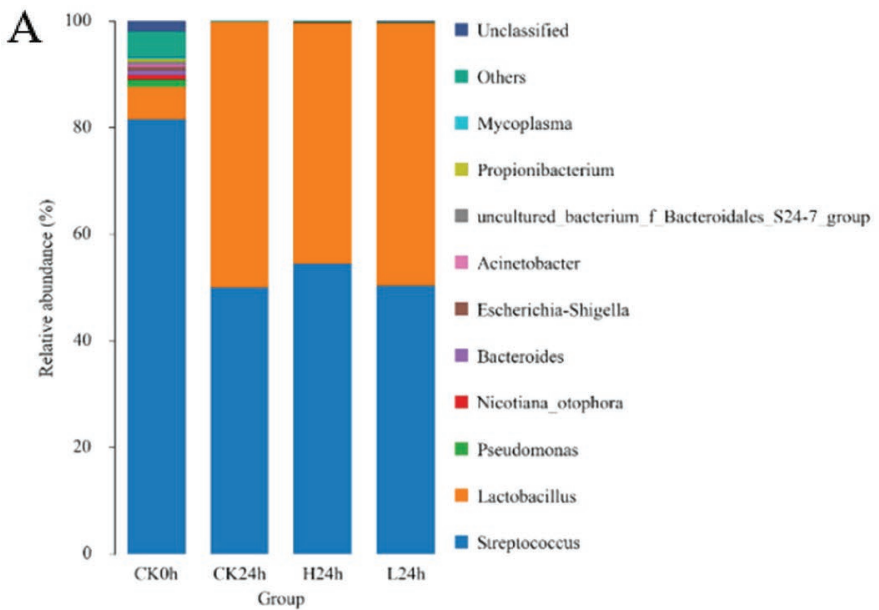

\section{Beta-Diversity of Bacteria Community}

Beta diversity, which reflects the degree of similarity between pairs of communities, was estimated by conducting principal component analysis and nonmetric multidimensional scaling between samples, and the results are displayed in Figure 4. In the 2 fermentation systems (commercial yogurt and baking powder as starters), CK24h, L24h, and H24h were close to each other and far from CKOh; TC24h, TL24h, and TH24h were close to each other and far from TC0h. The results of principal component analysis and nonmetric multidimensional scaling were consistent, and indicated

Figure 3. Bacterial composition of yogurt samples at genus level with different starters and concentrations of paclobutrazol $(\mathrm{A}=$ yogurt fermented with yogurt starter; $\mathrm{B}=$ yogurt fermented with baking powder). $\mathrm{CK}=$ yogurt fermented with yogurt starter, no contamination; $\mathrm{H}$ = yogurt fermented with yogurt starter, $4 \mathrm{mg} / \mathrm{kg}$ of paclobutrazol; $\mathrm{L}=$ yogurt fermented with yogurt starter, $2 \mathrm{mg} / \mathrm{kg}$ of paclobutrazol; TC = yogurt fermented with baking powder, no contamination; $\mathrm{TH}=$ yogurt fermented with baking powder, $4 \mathrm{mg} / \mathrm{kg}$ of paclobutrazol; TL $=$ yogurt fermented with baking powder, $2 \mathrm{mg} / \mathrm{kg}$ of paclobutrazol. $0 \mathrm{~h}$ indicates initial time of fermentation and $24 \mathrm{~h}$ indicates the end of the fermentation process. 
A

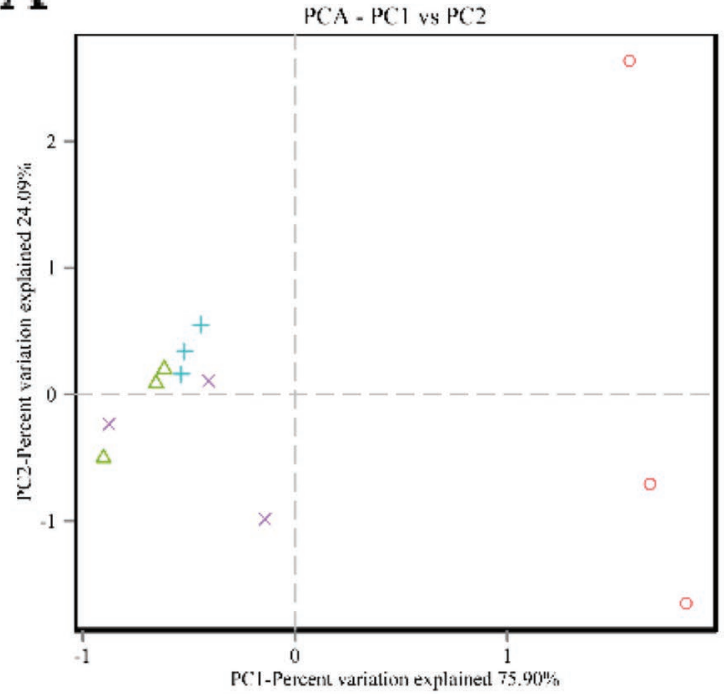

$\mathrm{C}$

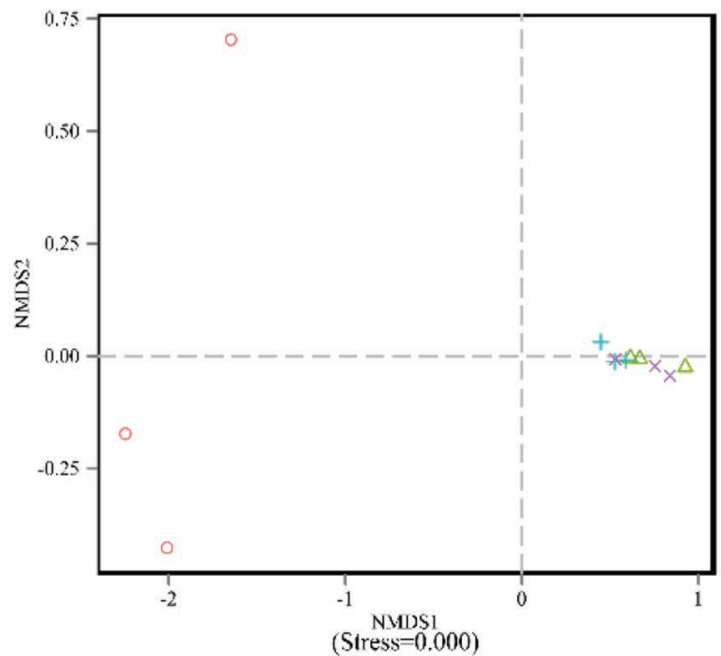

B

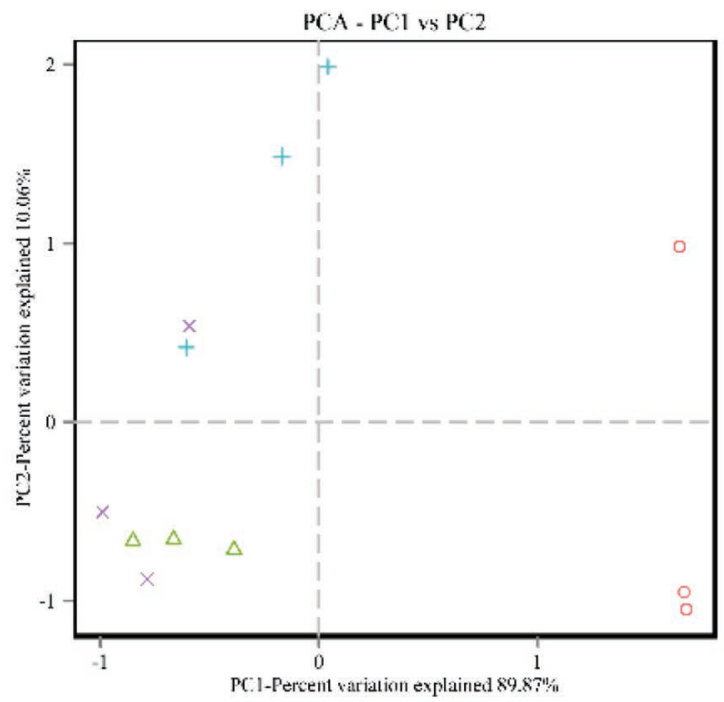

o TCOMh

$\triangle T C: 24$

$+\mathrm{TH} 2 \mathrm{Ah}$

$\times \mathrm{Tr} .2 \mathrm{hh}$

D

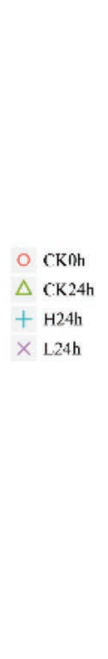

Figure 4. Principal component analysis (PCA) and nonmetric multidimensional scaling (NMDS) of yogurt samples $(\mathrm{A}=\mathrm{PCA}$ in $\mathrm{CK0h}$, CK24h, H24h, L24h; B = PCA in TC0h, TC24h, TH24h, TL24h; C = NMDS in CK0h, CK24h, H24h, L24h; D = NMDS in TC0h, TC24h, TH24h, TL24h). CK = commercial yogurt, no contamination; $\mathrm{H}=$ commercial yogurt, $4 \mathrm{mg} / \mathrm{kg}$ of paclobutrazol; $\mathrm{L}=$ commercial yogurt, 2 $\mathrm{mg} / \mathrm{kg}$ of paclobutrazol; $\mathrm{TC}=$ commercial baking powder, no contamination; $\mathrm{TH}=$ commercial baking powder, $4 \mathrm{mg} / \mathrm{kg}$ of paclobutrazol; TL $=$ commercial baking powder, $2 \mathrm{mg} / \mathrm{kg}$ of paclobutrazol. $0 \mathrm{~h}$ indicates initial time of fermentation and $24 \mathrm{~h}$ indicates the end of the fermentation process. $\mathrm{PC} 1=$ principal component $1 ; \mathrm{PC} 2=$ principal component 2.

that fermentation time played a more important role in bacterial diversity than did paclobutrazol.

\section{Functional Analysis of Cluster of Orthologous Groups and Kyoto Encyclopedia of Genes and Genomes}

To infer the functional genome composition and compare the differences between samples, PICRUSt software was used (Shen et al., 2017). In addition, the sequencing results were compared with Cluster of Orthologous Groups (COG) and Kyoto Encyclopedia of Genes and Genomes (KEGG) databases to predict the functions of sample bacteria. The pathway was analyzed on KOBAS version 2.0 web server (Xie et al., 2011).

From the COG analysis (Figure 5A), we concluded that the significant differences between CK24h and CK0h were mainly concentrated in cellular processes and signaling, metabolism, and information storage 
A

\section{$\square \mathrm{CK} 24 \mathrm{~h} \square \mathrm{CKOh}$}

Cell wall/membrane/envelope biogenesis Inorganic ion transport and metabolisn Amino acid transport and metabolism Carbohydrate transport and metabolism Transcription Signal transduction mechanism Posttranslational modification, protein tumover, chaperones Replication, recombination and repair Cell cycle control, cell division, chromosome partitioning Intracellular trafficking, secretion, and vesicular transport Cell motility

Coenzyme transport and metabolism

B Translation, ribosomal structure and biogenesis

$\mathrm{TCO}$

\section{$\square \mathrm{TC} 24$}

General function prediction only Cell eycle control, eell division, chromosome partitioning Inorganic ion transport and metabolism Posttranslational modification, protein turnover, chaperones Function unknown Translation, ribosomal structure and biogenesis Replication, recombination and repair Carbohydrate transport and metabolism Amino acid transport and metabolism Energy production and conversion Lipid transport and metabolism Intracellular traflicking, secretion, and vesicular transport

Cell wall/membrane/envelope biogenesis $\mathrm{RN} \wedge$ processing and modification Signal transduction mechanisms Coenzyme transport and metabolism Sccondary metabolites biosynthesis, transport and catabolism

C 0.0

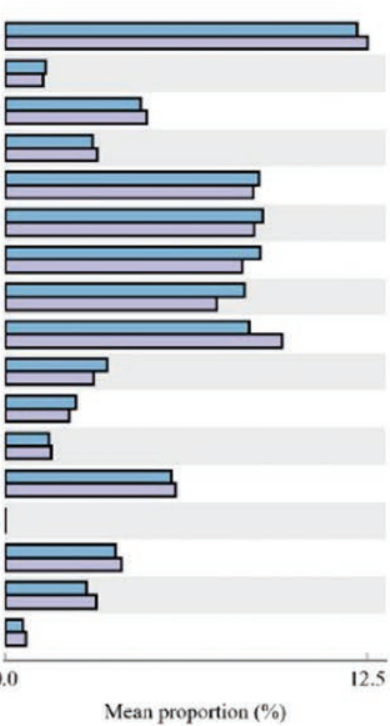

Mean proportion (\%)

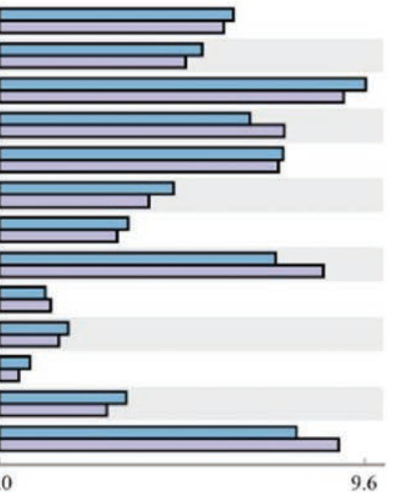

Mean proportion (\%)

\section{$\square$ TC24h $\square \mathrm{TH} 24 \mathrm{~h}$}

Cell cycle control, cell division, chromosome partitionin

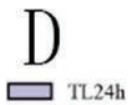

$\square \mathrm{TC} 24 \mathrm{~h}$

Coenzyme transport and metabolist Translation, ribosomal structure and biogenesis Signal transduction mechanisms Secondary metabolites biosynthesis, transport and catabolism Nucleotide transport and metabolism Cell motility 日

Intracellular trafficking, secretion, and vesicular transport Cell cycle control, cell division, chromosome partitioning Posttranslational modification, protein turnover, chaperones Cell wall/membrane/envelope biogenesis
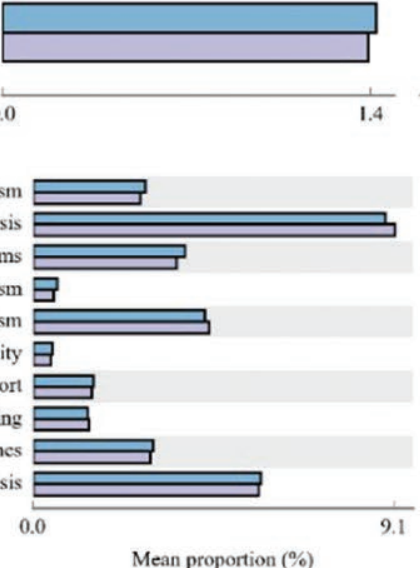
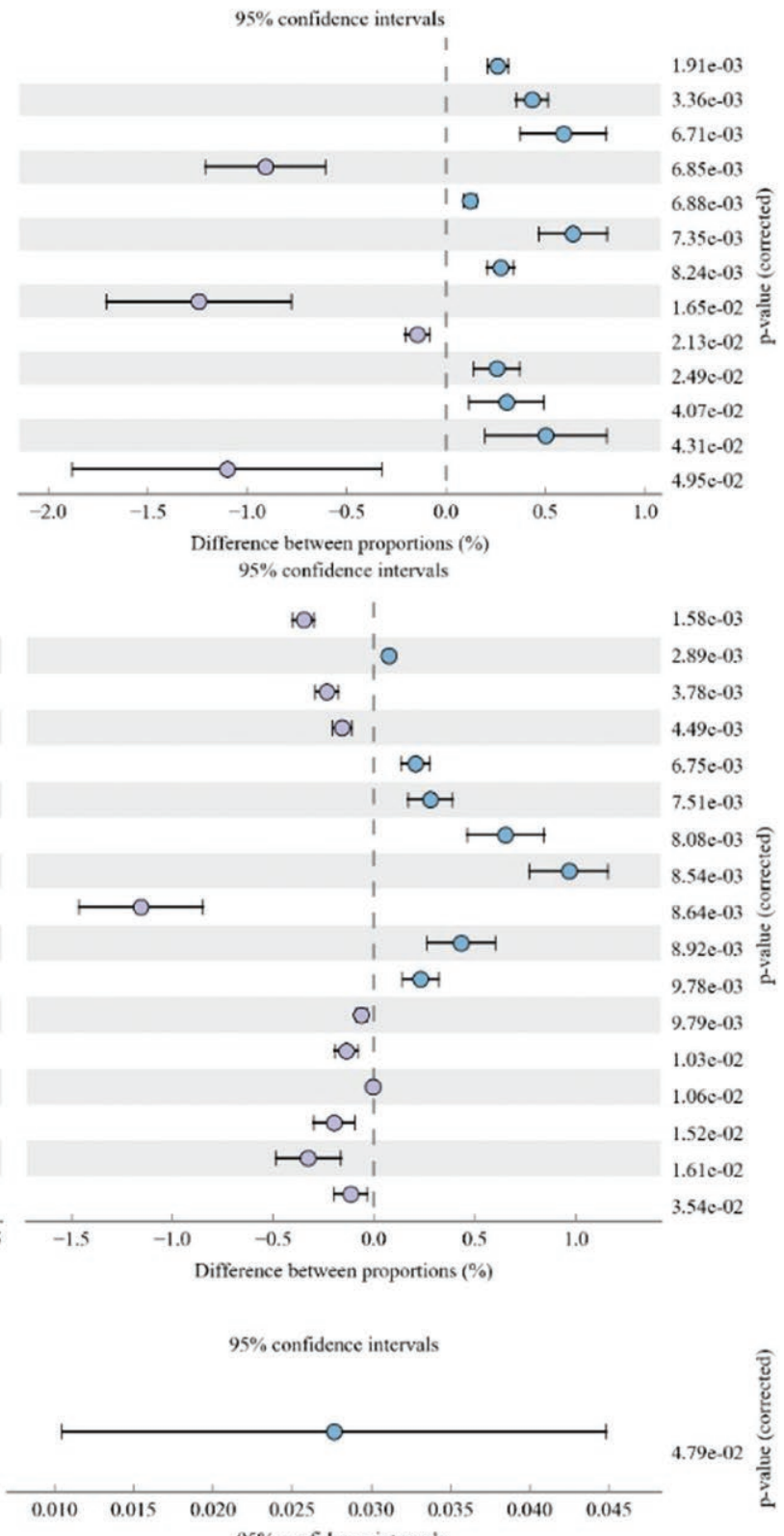
$95 \%$ confidence intervals

I 2.89e-03

a 어 $\quad 6.75 \mathrm{e}-03$ $\longrightarrow$ 8.08e-03 वे $\longmapsto \quad 8.54 \mathrm{e}-03$ $8.64 \mathrm{e}-03$ 응 $8.92 \mathrm{e}-03$ 를 $9.78 \mathrm{e}-03$ ․ $.79 \mathrm{e}-03$ $52 \mathrm{e}-02$ $61 \mathrm{e}-02$

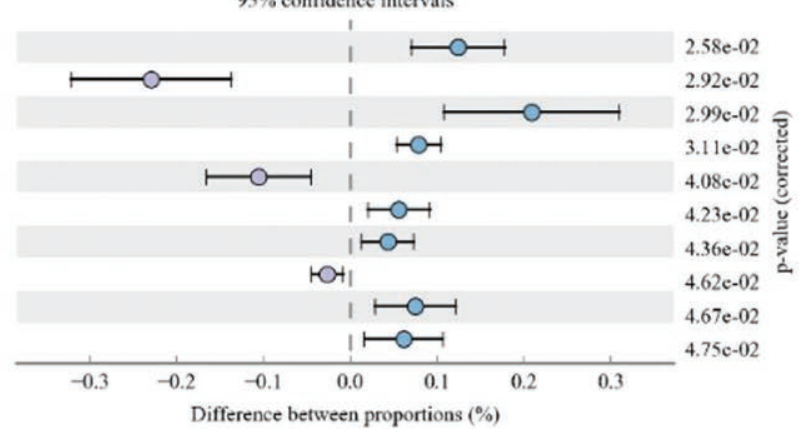
HOH 7.51e-03

Figure 5. The different functions of Cluster of Orthologous Groups (COG) between CK0h and CK24h (A); TC24h and TC0h (B); TH24h and TC24h (C); TL24h and TC24h (D). CK = commercial yogurt, no contamination; TC = commercial baking powder, no contamination; TH $=$ commercial baking powder, $4 \mathrm{mg} / \mathrm{kg}$ of paclobutrazol; $\mathrm{TL}=$ commercial baking powder, $2 \mathrm{mg} / \mathrm{kg}$ of paclobutrazol. $0 \mathrm{~h}$ indicates initial time of fermentation and $24 \mathrm{~h}$ indicates the end of the fermentation process. 
A

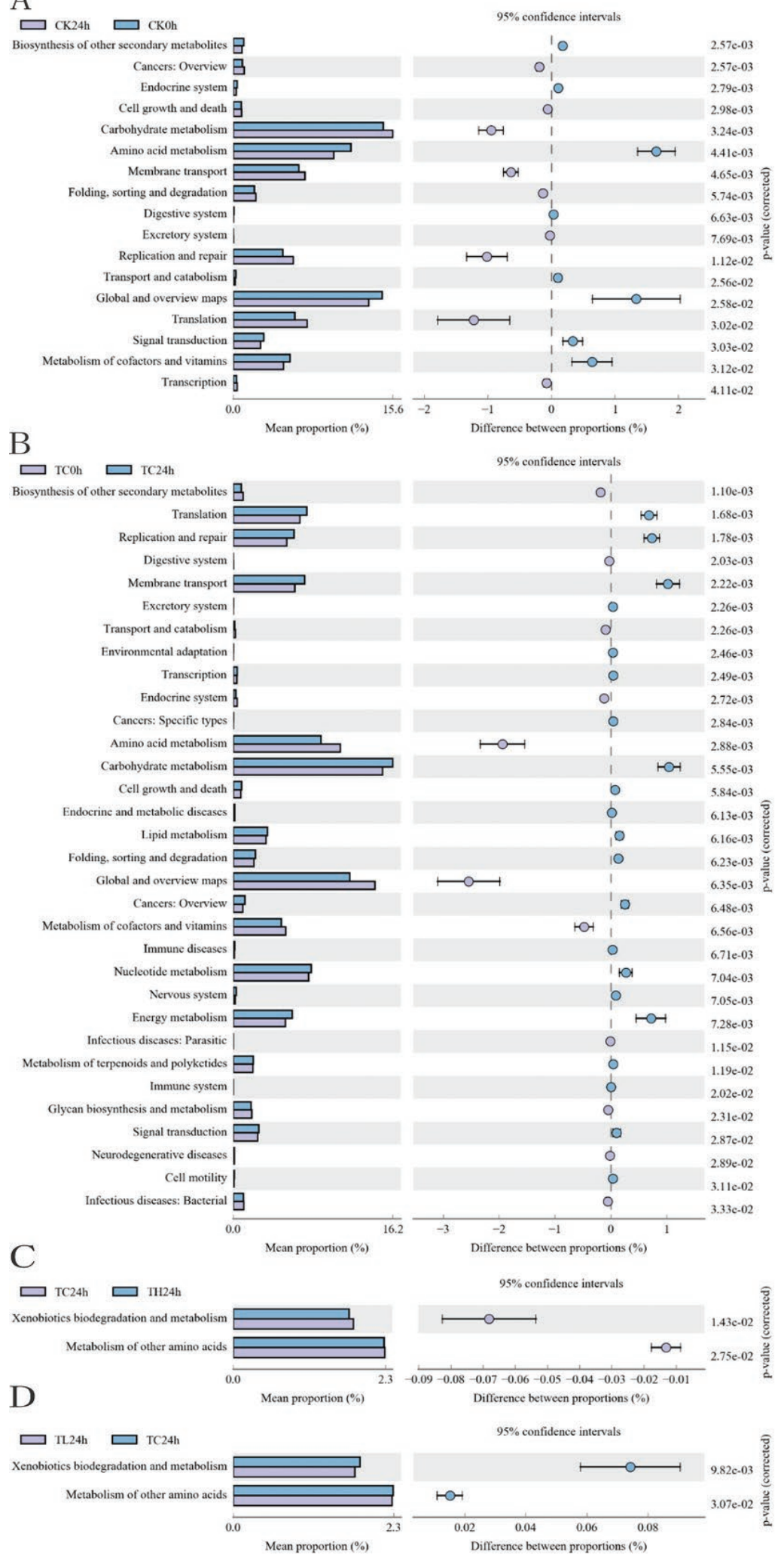

Figure 6. The different functions of Kyoto Encyclopedia of Genes and Genomes (KEGG): between CK0h and CK24h (A); TC24h and TC0h (B); TC24h and TH24h (C); TL24h and TC24h (D). CK = commercial yogurt, no contamination; TC = commercial baking powder, no contamination; $\mathrm{TH}=$ commercial baking powder, $4 \mathrm{mg} / \mathrm{kg}$ of paclobutrazol; TL $=$ commercial baking powder, $2 \mathrm{mg} / \mathrm{kg}$ of paclobutrazol. $0 \mathrm{~h}$ indicates initial time of fermentation and $24 \mathrm{~h}$ indicates the end of the fermentation process. 
and processing (3 aspects of 13 functions). Compared with CK0h, CK24h was significantly enriched in carbohydrate transport and metabolism, replication, recombination and repair, cell cycle control, cell division, and chromosome partitioning. Moreover, compared with the H24h treatment, L24h and CK24h had no significant influence on COG functions. We conjectured that the degradation of paclobutrazol was not significant during fermentation and might be related to these results.

For the samples that used baking powder, compared with TC0h, TC24h was significantly enriched in carbohydrate transport and metabolism, indicating that carbohydrate transport and metabolism were crucial functions as fermentation progressed (Figure 5B). Compared with TC24h, both samples spiked with paclobutrazol (TH24h and TL24h) were significantly enriched the functions of cell cycle control, cell division, and chromosome partitioning (Figure 5C), demonstrating that addition of paclobutrazol could promote these functions. In addition, 10 functions differed between TC24h and TL24h (Figure 5D), including significant enrichment of translation, ribosomal structure and biogenesis, nucleotide transport and metabolism, cell cycle control, cell division, and chromosome partitioning in TL24h.

The results of the KEGG analysis are shown in Figure 6. Compared with CK0h, CK24h was significantly enriched in metabolism, human diseases, organismal systems, cellular processes, environmental information processing, genetic information process, environmental information processing, and genetic information processing (Figure 6A). The main metabolic pathway functions of CK24h were enriched in carbohydrate metabolism, replication and repair, and translation. For CK0h, the main enrichments were amino acid metabolism, global and overview maps, and metabolism of cofactors and vitamins. For KEGG function prediction, carbohydrate metabolism was significantly enriched in CK24h, which was the same as COG function prediction. In addition, compared with H24h, L24h and CK24h had no significant influence on KEGG function, which was the same as COG. From analysis of the KEGG metabolic pathway, we confirmed that the lack of change in paclobutrazol concentration during yogurt fermentation process was related to the relative absence of microbial degradation.

The main differences of KEGG functions between TC24h and TC0h are shown in Figure 6B. The function significantly enriched in TC24h was carbohydrate metabolism, while the function more enriched in $\mathrm{TCOh}$ was AA transport and metabolism. The differences between TC24h and TH24h were the same as those for TC24h and TL24h (Figure 6C). Compared with TC24h and TL24h (Figure 6D), the functions of TC24h were significantly enriched in xenobiotics biodegradation and metabolism. The above results show that the addition of paclobutrazol could inhibit xenobiotic biodegradation and metabolism, which further explained why paclobutrazol did not degrade during yogurt fermentation. The related mechanisms need to be further investigated.

\section{CONCLUSIONS}

In this study, we explored the effect of paclobutrazol on yogurt fermentation. The results illustrated that the concentration of the 2 isomers showed no visible degradation, and there were no significant stereoselective behaviors occurring in any of the samples. We explained the lack of degradation of paclobutrazol in the context of microbial composition and function, and found that stable residues of paclobutrazol can cause potential food safety risks. Paclobutrazol did affect microbial community structure during yogurt fermentation. However, microbial $\alpha$-diversity analysis indicated that fermentation time played a more important role in diversity than paclobutrazol concentration. Relative abundances of Staphylococcus were significantly increased in paclobutrazol-added samples when commercial baking powder was used as a starter, bringing potential risk to the quality of yogurt. Moreover, the addition of paclobutrazol inhibited some functions of microorganisms, including xenobiotic biodegradation and metabolism, which might mean that some pollutants, including paclobutrazol, could not degrade during fermentation. Based on the above results, we infer that presence of paclobutrazol residues could weaken microbial degradation and metabolism in yogurt, and the presence of Staphylococcus may pose a risk to food safety.

\section{ACKNOWLEDGMENTS}

The present study was supported by grants from the National Key R\&D Program of China [2017YFD020030803] and National Natural Science Foundation of China [No.21507032]. All authors declare that they have no conflicts of interest.

\section{REFERENCES}

Belli, P., A. F. A. Cantafora, S. Stella, S. Barbieri, and C. Crimella. 2013. Microbiological survey of milk and dairy products from a small scale dairy processing unit in Maroua (Cameroon). Food Control 32:366-370. https://doi.org/10.1016/j.foodcont.2012.12 .021 .

Benozzi, E., A. Romano, V. Capozzi, S. Makhoul, L. Cappellin, I. Khomenko, E. Aprea, M. Scampicchio, G. Spano, T. D. Märk, F. Gasperi, and F. Biasioli. 2015. Monitoring of lactic fermentation driven by different starter cultures via direct injection mass 
spectrometric analysis of flavour-related volatile compounds. Food Res. Int. 76:682-688. https://doi.org/10.1016/j.foodres.2015.07 .043 .

Borsa, B. A., B. G. Tuna, F. J. Hernandez, L. I. Hernandez, G. Bayramoglu, M. Y. Arica, and V. C. Ozalp. 2016. Staphylococcus aureus detection in blood samples by silica nanoparticle-oligonucleotides conjugates. Biosens. Bioelectron. 86:27-32. https://doi.org/10 $.1016 /$ j.bios.2016.06.023.

Bourrie, B. C. T., B. P. Willing, and P. D. Cotter. 2016. The microbiota and health promoting characteristics of the fermented beverage kefir. Front. Microbiol. 7:647. https://doi.org/10.3389/fmicb .2016.00647.

Chen, S., H. Chen, Z. Chen, Y. Wen, and W. Liu. 2019. Enantioselective phytotoxic disturbances of fatty acids in Arabidopsis thaliana by dichlorprop. Environ. Sci. Technol. 53:9252-9259. https://doi .org/10.1021/acs.est.9b03744

Danneskiold-Samsøe, N. B., H. Dias de Freitas Queiroz Barros, R. Santos, J. L. Bicas, C. B. B. Cazarin, L. Madsen, K. Kristiansen, G. M. Pastore, S. Brix, and M. R. Maróstica Júnior . 2019. Interplay between food and gut microbiota in health and disease. Food Res. Int. 115:23-31. https://doi.org/10.1016/j.foodres.2018 .07 .043 .

Di, S. S., T. Cang, P. P. Qi, Z. W. Wang, X. Y. Wang, M. F. Xu, X. Q. Wang, H. Xu, and Q. Wang. 2019. Comprehensive study of isocarbophos to various terrestrial organisms: Enantioselective bioactivity, acute toxicity, and environmental behaviors. J. Agric. Food Chem. 67:10997-11004. https://doi.org/10.1021/acs.jafc.9b02931.

Gao, M., Y. Lin, G. Z. Shi, H. H. Li, Z. B. Yang, X. X. Xu, J.-R. Xian, Y.-X. Yang, and Z. Cheng. 2019. Bioaccumulation and health risk assessments of trace elements in housefly (Musca domestica L.) larvae fed with food wastes. Sci. Total Environ. 682:485-493. https:/ /doi.org/10.1016/j.scitotenv.2019.05.182.

Gilley, A., and R. A. Fletcher. 1998. Gibberellin antagonizes paclobutrazol-induced stress protection in wheat seedlings. J. Plant Physiol. 153:200-207. https://doi.org/10.1016/S0176-1617(98)80066-7.

Grispoldi, L., P. A. Popescu, M. Karama, V. Gullo, G. Poerio, E. Borgogni, P. Torlai, G. Chianese, A. G. Fermani, P. Sechi, and B. Cenci-Goga. 2019. Study on the growth and enterotoxin production by staphylococcus aureus in canned meat before retorting. Toxins (Basel) 11:291. https://doi.org/10.3390/toxins11050291.

Guidi, F., A. Duranti, S. Gallina, Y. Nia, A. Petruzzelli, A. Romano, V. Travaglini, A. Olivastri, V. Calvaresi, L. Decastelli, and G. Blasi. 2018. Characterization of a staphylococcal food poisoning outbreak in a workplace canteen during the post-earthquake reconstruction of central Italy. Toxins (Basel) 10:523. https://doi.org/10 $.3390 /$ toxins10120523.

Kergourlay, G., B. Taminiau, G. Daube, and M. C. Champomier Vergès. 2015. Metagenomic insights into the dynamics of microbial communities in food. Int. J. Food Microbiol. 213:31-39. https:// doi.org/10.1016/j.ijfoodmicro.2015.09.010.

Kuo, J., Y. W. Wang, M. Chen, G. Fuh, and C. H. Lin. 2019. The effect of paclobutrazol on soil bacterial composition across three consecutive flowering stages of mung bean. Folia Microbiol. (Praha) 64:197-205. https://doi.org/10.1007/s12223-018-0644-x.

Lei, Z., D. Zhang, B. Lu, W. Zhou, and D. Wang. 2018. Activation of mast cells in skin abscess induced by Staphylococcus aureus (S. aureus) infection in mice. Res. Vet. Sci. 118:66-71. https://doi.org/ 10.1016/j.rvsc.2018.01.016.

Leite, A. M. O., B. Mayo, C. T. C. C. Rachid, R. S. Peixoto, J. T. Silva, V. M. F. Paschoalin, and S. Delgado. 2012. Assessment of the microbial diversity of Brazilian kefir grains by PCR-DGGE and pyrosequencing analysis. Food Microbiol. 31:215-221. https:/ /doi.org/10.1016/j.fm.2012.03.011.

Liu, C., S. Liu, and J. Diao. 2019. Enantioselective growth inhibition of the green algae (Chlorella vulgaris) induced by two paclobutrazol enantiomers. Environ. Pollut. 250:610-617. https://doi.org/10 .1016/j.envpol.2019.04.027.

Liu, W., X. Xi, Q. Sudu, L. Kwok, Z. Guo, Q. Hou, B. Menhe, T. Sun, and H. Zhang. 2015. High-throughput sequencing reveals microbial community diversity of Tibetan naturally fermented yak milk.
Ann. Microbiol. 65:1741-1751. https://doi.org/10.1007/s13213 -014-1013-x.

Marsh, A. J., O. O'Sullivan, C. Hill, R. P. Ross, and P. D. Cotter. 2013. Sequencing-based analysis of the bacterial and fungal composition of kefir grains and milks from multiple sources. PLoS One 8:e69371. https://doi.org/10.1371/journal.pone.0069371.

McMurtrie, E. K., S. D. Johanningsmeier, F. Breidt Jr., and R. E. Price. 2019. Effect of brine acidification on fermentation microbiota, chemistry, and texture quality of cucumbers fermented in calcium or sodium chloride brines. J. Food Sci. 84:1129-1137. https:/ /doi.org/10.1111/1750-3841.14600.

Meng, X., G. Yang, F. Li, T. Liang, W. Lai, and H. Xu. 2017. Sensitive detection of Staphylococcus aureus with vancomycin-conjugated magnetic beads as enrichment carriers combined with flow cytometry. ACS Appl. Mater. Interfaces 9:21464-21472. https://doi.org/ 10.1021/acsami.7b05479.

Muñoz-Leoz, B., E. Ruiz-Romera, I. Antigüedad, and C. Garbisu. 2011. Tebuconazole application decreases soil microbial biomass and activity. Soil Biol. Biochem. 43:2176-2183. https://doi.org/10 .1016/j.soilbio.2011.07.001.

Pastells, C., G. Acosta, N. Pascual, F. Albericio, M. Royo, and M. P. Marco. 2015. An immunochemical strategy based on peptidoglycan synthetic peptide epitopes to diagnose Staphylococcus aureus infections. Anal. Chim. Acta 889:203-211. https://doi.org/10 .1016/j.aca.2015.07.049.

Pimentel, D. 1995. Amounts of pesticides reaching target pests: Environmental impacts and ethics. J. Agric. Environ. Ethics 8:17-29. https://doi.org/10.1007/BF02286399.

Russell, R. J., C. Scott, C. J. Jackson, R. Pandey, G. Pandey, M. C. Taylor, C. W. Coppin, J.-W. Liu, and J. G. Oakeshott. 2011. The evolution of new enzyme function: Lessons from xenobiotic metabolizing bacteria versus insecticide-resistant insects. Evol. Appl. 4:225-248. https://doi.org/10.1111/j.1752-4571.2010.00175.x.

Schelin, J., Y. B. Susilo, and S. Johler. 2017. Expression of staphylococcal enterotoxins under stress encountered during food production and preservation. Toxins (Basel) 9:401. https://doi.org/10 $.3390 /$ toxins9120401.

Shen, H., Z. Y. Lu, Z. Chen, and Z. M. Shen. 2017. Associations among dietary non-fiber carbohydrate, ruminal microbiota and epithelium G-protein-coupled receptor, and histone deacetylase regulations in goats. Microbiome 5:123. https://doi.org/10.1186/ s40168-017-0341-z.

Srisuvor, N., N. Chinprahast, C. Prakitchaiwattana, and S. Subhimaros. 2013. Effects of inulin and polydextrose on physicochemical and sensory properties of low-fat set yoghurt with probiotic-cultured banana purée. Lebensm. Wiss. Technol. 51:30-36. https:// doi.org/10.1016/j.lwt.2012.10.018.

Sugavanam, B. 1984. Diastereoisomers and enantiomers of paclobutrazol: Their preparation and biological activity. J. Pestic. Sci 15:296-302. https://doi.org/10.1002/ps.2780150312.

Tejada, M., E. Morillo, I. Gómez, F. Madrid, and T. Undabeytia. 2017. Effect of controlled release formulations of diuron and alachlor herbicides on the biochemical activity of agricultural soils. J. Hazard. Mater. 322:334-347. https://doi.org/10.1016/j.jhazmat .2016.10.002.

Wang, X., P. Qi, G. Yang, X. Wang, H. U. Zhang, H. A. O. Xu, Z. Wang, and Q. Wang. 2014. Enantioselective degradation of (2 RS, 3 RS)-paclobutrazol in peach and mandarin under field conditions. Chirality 26:400-404. https://doi.org/10.1002/chir.22339.

Wertheim, H. F. L., D. C. Melles, M. C. Vos, W. Van Leeuwen, A. Van Belkum, H. A. Verbrugh, and J. L. Nouwen. 2005. The role of nasal carriage in Staphylococcus aureus infections. Lancet Infect. Dis. 5:751-762. https://doi.org/10.1016/S1473-3099(05)70295-4.

Wolfe, B. E., J. E. Button, M. Santarelli, and R. J. Dutton. 2014. Cheese rind communities provide tractable systems for in situ and in vitro studies of microbial diversity. Cell 158:422-433. https:// doi.org/10.1016/j.cell.2014.05.041.

Wu, S., M. Yu, H. U. Zhang, J. Han, and M. Qian. 2015. Enantioselective degradation of (2 RS, 3 RS)-paclobutrazol in rat liver microsomes. Chirality 27:344-348. https://doi.org/10.1002/chir.22440. 
Xie, C., X. Z. Mao, J. J. Huang, Y. Ding, J. M. Wu, S. Dong, L. Kong, G. Gao, C. Y. Li, and L. P. Wei. 2011. KOBAS 2.0: A web server for annotation and identification of enriched pathways and diseases. Nucleic Acids Res. 39:316-322. https://doi.org/10.1093/ nar/gkr483.

Xiong, J., L. Xiong, H. Zhou, Y. Liu, and L. Wu. 2018. Occurrence of aflatoxin B1 in dairy cow feedstuff and aflatoxin M1 in UHT and pasteurized milk in central China. Food Control 92:386-390. https: //doi.org/10.1016/j.foodcont.2018.05.022.

Yang, Z. H., and G. Ji. 2015. Stereoselective degradation and molecular ecological mechanism of chiral pesticides beta-cypermethrin in soils with different pH Values. Environ. Sci. Technol. 49:1416614175. https://doi.org/10.1021/acs.est.5b04672.

Yun, Y., D. Yin, D. H. Dawood, X. Liu, Y. Chen, and Z. Ma. 2014. Functional characterization of FgERG3 and FgERG5 associated with ergosterol biosynthesis, vegetative differentiation and virulence of Fusarium graminearum. Fungal Genet. Biol. 68:60-70. https://doi.org/10.1016/j.fgb.2014.04.010.

Zhang, T., C. H. Jeong, W. N. Cheng, H. Bae, H. G. Seo, M. C. Petriello, and S. G. Han. 2019. Moringa extract enhances the fermentative, textural, and bioactive properties of yogurt. LWT 101:276-284. https://doi.org/10.1016/j.lwt.2018.11.010.

Zhi, W., Z. Ge, Z. He, and H. Zhang. 2014. Methods for understanding microbial community structures and functions in microbial fuel cells: A review. Bioresour. Technol. 171: 461-468. https://doi.org/ 10.1016/j.biortech.2014.08.096.

Zhi, W., and G. Ji. 2012. Constructed wetlands, 1991-2011: A review of research development, current trends, and future directions. Sci. Total Environ. 441:19-27. https://doi.org/10.1016/j.scitoteny .2012.09.064.

Zhi, W., L. Yuan, G. Ji, and C. He. 2015. Enhanced long-term nitrogen removal and its quantitative molecular mechanism in tidal flow constructed wetlands. Environ. Sci. Technol. 49:4575-4683. https://doi.org/10.1021/acs.est.5b00017.

\section{ORCIDS}

Zhong-Hua Yang @ https://orcid.org/0000-0002-7932-9110 